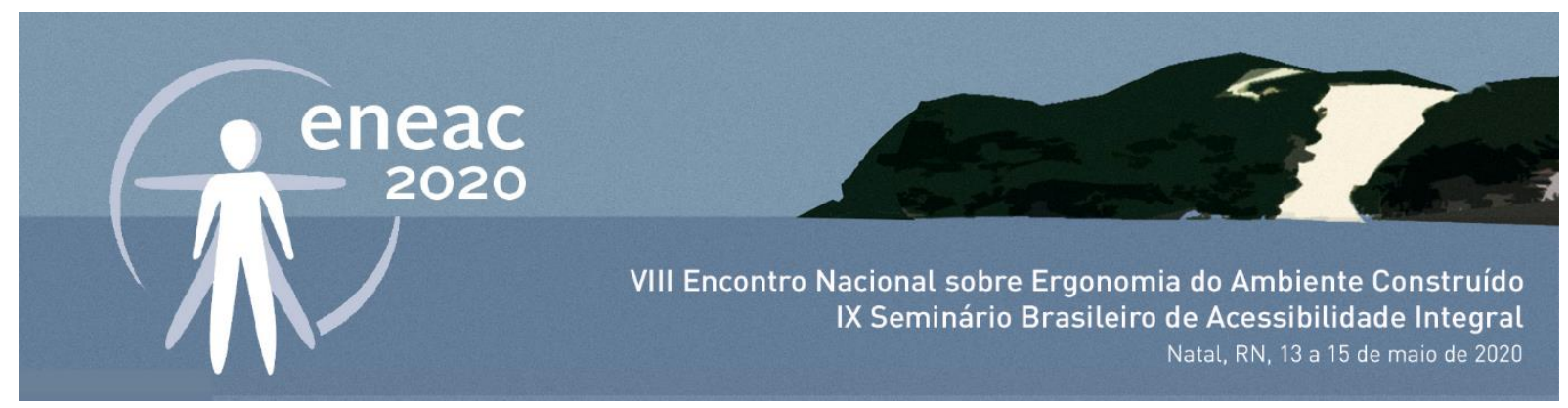

\title{
A ABNT NBR 9050: A difusão da acessibilidade pela Norma
}

\author{
The ABNT NBR 9050: The dissemination of accessibility by the \\ Standard
}

\begin{abstract}
JÚLIO CEZAR MACEDO RODRIGUES
Arquiteto e Urbanista, Mestrando em Arquitetura, Tecnologia e Cidade, Faculdade de Engenharia Civil, Arquitetura e Urbanismo, Universidade Estadual de Campinas, jcm.rodrigues13@gmail.com
\end{abstract}

NÚBIA BERNARDI

Arquiteta e Urbanista, Docente na Faculdade de Engenharia Civil, Arquitetura e Urbanismo, Universidade Estadual de Campinas, nubiab@unicamp.br

\begin{abstract}
RESUMO
A Acessibilidade e o Desenho Universal conformam justiça ao garantir direitos fundamentais, individuais e coletivos no contexto edificado. Nessa perspectiva o entendimento de seu aparato legal é de fundamental importância para o assunto, principalmente em situações de não compreensão das necessidades das pessoas com deficiência ou mobilidade reduzida. Para além da função de estabelecer diretrizes, os textos legais possuem a atribuição de difundir conhecimento, suprindo as carências de seus intérpretes. $O$ presente artigo contempla uma pesquisa bibliográfica referente às quatro versões da norma técnica ABNT NBR 9050 e enfatiza a forma como o texto adquiriu um caráter pedagógico, contudo sem condições em atender todas as complexas facetas da realidade. Os responsáveis pela produção do edificado precisam compreender as normas de acessibilidade ao meio físico, não como um fim em si, mas como um dos instrumentos para o desenvolvimento de projetos e obras que de fato atendam a todos, respeitando singularidades.
\end{abstract}

PALAVRAS-CHAVE: Acessibilidade; Desenho Universal; Norma; ABNT NBR 9050

\section{ABSTRACT}

Accessibility and Universal Design conform justice by guaranteeing fundamental, individual and collective rights in the built environment. In this perspective, the understanding of its legal apparatus is of fundamental importance for the subject, especially in situations of not understanding the needs of people with disabilities or reduced mobility. Beyond the function of establishing guidelines, legal texts have the function of spreading knowledge, supplying the needs of their interpreters. This article contemplates a bibliographic research referring to the four versions of the technical standard $A B N T$ NBR 9050 and emphasizes how the text acquired a pedagogical character; however, the text is unable to meet all the complex facets of reality. Those responsible for the production of the environment 


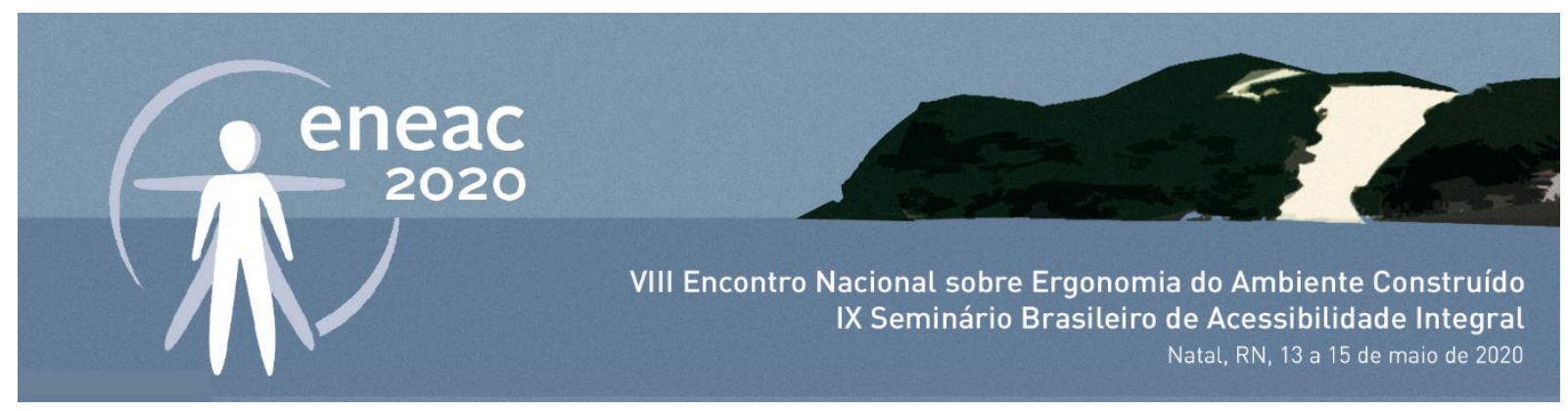

need to understand the standards of accessibility to the physical environment, not as an end in itself, but as one of the instruments for the development of projects and buildings that actually serve everyone, respecting singularities.

KEYWORDS: Accessibility; Universal Design; Standards; ABNT NBR 9050

\section{INTRODUÇÃO}

A peculiaridade faz parte do mundo natural e embora a diversidade de formas, cores e texturas seja uma constante, inclusive para o ser humano, ao longo da história, por diferentes motivos padrões foram estabelecidos. Se de um lado existe um modelo, definido pela maioria, do outro surge a minoria distante desses requisitos. Nessa dualidade surge a justiça, a tentativa de estabelecer a igualdade, utilizando critérios previamente definidos, dentre eles, os instrumentos legais.

Quando a expressão Acessibilidade deixou de designar somente o ato de chegar, de se aproximar e agregou o significado de favorecer o acesso das pessoas com deficiência ou mobilidade reduzida, adquiriu a condição de justiça, com a garantia de direitos fundamentais, individuais e coletivos. Essa perspectiva se estendeu ao Desenho Universal ou Universal Designi, uma filosofia criada nos Estados Unidos para o desenvolvimento de produtos e ambientes que englobam a Acessibilidade, para atender as necessidades do maior número de pessoas, independentemente de suas características ou habilidades particulares (MACE; HARDIE; PLACE, 1991).

Nessa dinâmica o aparato legal assume um papel fundamental para a Acessibilidade e o Desenho Universal, com a uniformização e difusão de entendimentos e diretrizes relacionadas à produção do espaço construído, principalmente em um contexto de pouco conhecimento. $O$ assunto é reconhecido pelo Ministério da Educação na Resolução no 2/2010 como de atribuição dos Arquitetos e Urbanistas, contudo somente está sendo explicitado no conteúdo curricular mínimo da respectiva graduação, a partir de $2020^{i i}$. Segundo Dorneles (2014) nessa falta ou demora na implantação de obrigações relacionadas ao ensino, o assunto passou a fazer parte dos cursos de Arquitetura, em disciplinas ditas eletivas ou em conteúdo programático de disciplinas de projeto, possivelmente em resposta às imposições legais para as edificações. Algo semelhante é observado por Padoam (2018), na Engenharia Civil.

Se as determinações do aparato legal influenciaram na introdução gradual da Acessibilidade e do Desenho Universal no contexto universitário, no ambiente profissional, tornou-se um elemento fundamental. Como cursos complementares ou pós-graduações na área não são requisitos para a atuação, muitos compreendem o assunto somente pelos requisitos legais necessários para a aprovação de projetos juntos ao órgão públicos.

Diante dessa questão os mecanismos legais de Acessibilidade e Desenho Universal foram evoluindo, adquirindo um viés pedagógico, indo ao encontro das necessidades de seus intérpretes. $O$ fato pode ser observado nessa pesquisa bibliográfica que descreve as principais redações nacionais para o assunto priorizando a trajetória da ABNT NBR 9050:2015, atualmente intitulada "Acessibilidade a edificação, mobiliário, espaço e equipamentos urbanos". 


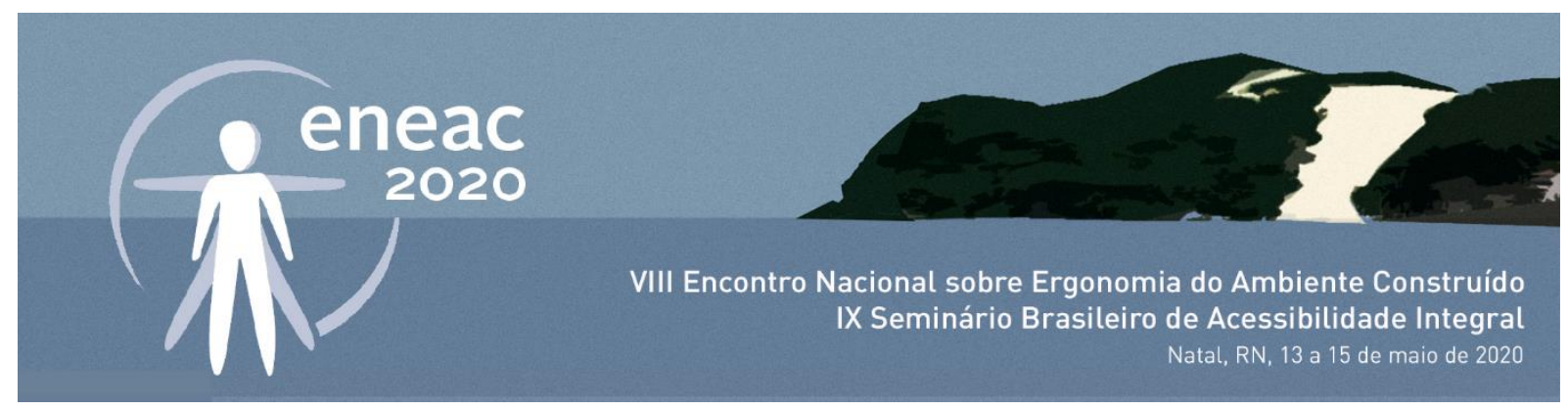

\section{DOS ANTECEDENTES LEGAIS AO ESTABELECIMENTO DO APARATO TÉCNICO}

Textos com diretrizes para o tratamento concedido às pessoas com deficiência não são novidade. De acordo com Silva (1987), papiros egípcios antigos com recomendações morais já consideravam o assunto. Leis gregas e romanas proviam assistência financeira aos soldados que retornavam inválidos das batalhas, ao mesmo tempo que permitiam a eliminação dos recém-nascidos deficientes. Essas questões, que consolidam no plano legal o entendimento de uma determinada época ou nação, foram sendo ampliadas com o tempo. Atualmente, tanto no contexto internacional como nacional, nas esferas federal, estaduais e municipais existem aparatos legais e técnicos específicos relacionados ao assunto.

\section{O aparato legal nacional}

A interação entre pessoas com deficiência e ambiente foi introduzida à Constituição Federal Brasileira pela primeira vez em 1978 com a Emenda Constitucional no 12. Contudo, o pequeno parágrafo que acrescentou o assunto à Constituição de 1967 não motivou maiores detalhamentos hierarquicamente inferiores à Constituição, possivelmente por ser uma proposta sem a participação popular, realizada pelo Deputado Federal Thales Ramalho, após se tornar usuário de cadeiras de rodas. Algo diferente do que ocorre com o texto subsequente, de 1988, uma resultante da atuação de vários representantes da sociedade, como pode ser observado na Figura 1.

No final da década de 1970 e início de 1980 grupos marginalizados da população brasileira iniciaram movimentos sociais em luta por seus direitos, dentre eles os relacionados às pessoas com deficiência (CRESPO, 2009). A difusão de conteúdo promovida pela ONU no Ano (1981) como a Década para as Pessoas com Deficiência (1983 a 1992) fomentaram esse processo. Na redação de 1988 a Acessibilidade passou a ser considerada tanto no Artigo 227 referente às novas edificações como no Artigo 244 para as já existes, em uma disposição que impossibilita a aplicação do princípio do direito (ARAUJO, 1997). Edificações inacessíveis anteriores à lei deveriam passar por adequações.

Um ano após a promulgação da nova Constituição é aprovado o seu primeiro desdobramento referente ao assunto, ou seja, um texto infraconstitucional. A Lei $n^{\circ} 7.853$ de 1989 passou a criminalizar a discriminação às pessoas com deficiência e definiu que os Censos contemplassem questões específicas ao assunto. Após dez anos entrou em vigor o Decreto n 3.298/1999 com diretrizes para a acessibilidade, porém restritas às edificações ocupadas pela administração pública federal e suas instituições de ensino, o que mudou em 2000.

A Lei no 10.098/2000, estabeleceu critérios ao ambiente construído público, como em vias e parques ou em locais de uso coletivo como elevadores em edifícios habitacionais multifamiliares. Entretanto, eram necessários maiores detalhamentos legais definidos posteriormente em 2004 com o Decreto no 5.296. Dentre suas diretrizes o texto modificou as anotações de responsabilidades técnicas das entidades de fiscalização das áreas de Engenharia e Arquitetura, que passaram a incluir campo para o profissional declarar o atendendo das regras de acessibilidade.

Em 2015 foi sancionado a Lei no 13.146, conhecida por Lei Brasileira de inclusão (LBI) ou Estatuto da Pessoa com Deficiência (BRASIL, 2015). O texto é a resultante de um processo com origem nacional iniciado em 2000 na Câmara de Deputados Federais e outro internacional quando o Brasil ratificou em 2008 com o Decreto Legislativo no 186 a Convenção sobre os Direitos das Pessoas com Deficiência, promulgada pela ONU em 2007. Atualmente é a principal legislação nacional brasileira 


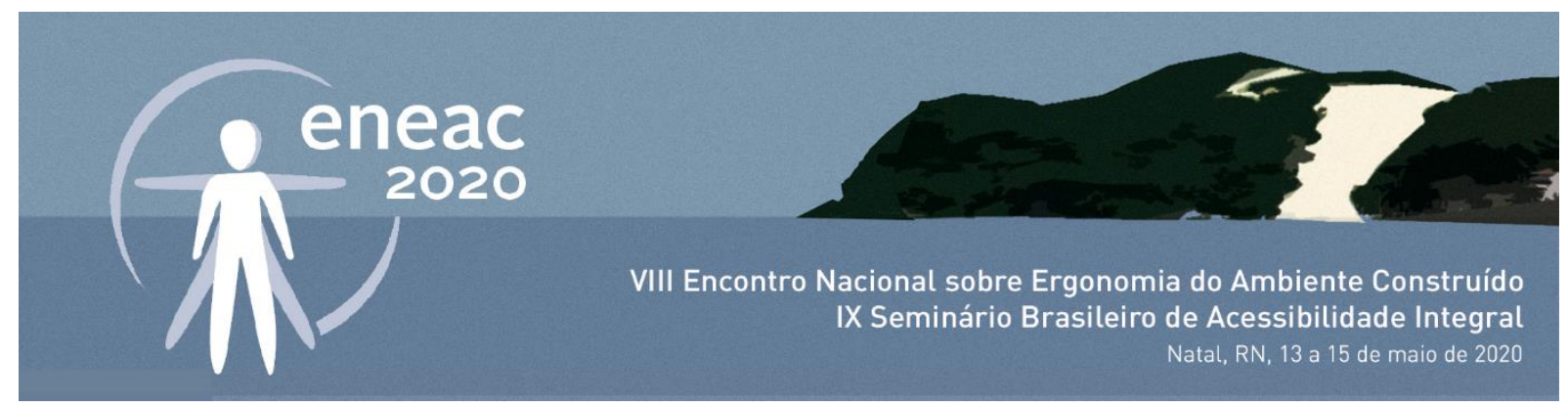

para a temática, tendo alterado várias outras redações como a Lei $n^{\circ} 10.257 / 2001$, o Estatuto das Cidades, que passou a tornar obrigatório junto aos Planos Diretores, um Plano de Rotas Acessíveis e a Lei ${ }^{\circ} 8.429$ de 1992, a Lei da Improbidade Administrativa que tornou o descumprimento dos requisitos de acessibilidade em obras públicas crime punível com multas, até a perda da função pública ou dos direitos políticos por três a cinco anos.

Figura 1 - Sequência com as principais regulações nacionais para acessibilidade ao ambiente construído, diferenciando as constitucionais, e

CONSTITUCIONAL

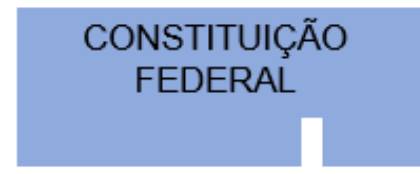

1988

\section{as infraconstitucionais}

INFRACONSTITUCIONAIS

$\begin{array}{cccccc}\text { LEI N }^{\circ} & \begin{array}{c}\text { DECRETO } \\ 7.853\end{array} & \begin{array}{c}\text { LEIS N } \\ N^{0} 3.298 \\ 10.048 \mathrm{E} \\ 10.098\end{array} & \begin{array}{c}\text { DECRETO } \\ \text { N }^{0} 5.296\end{array} & \begin{array}{c}\text { DECRETO } \\ \text { N }^{0} 186\end{array} & \begin{array}{c}\text { LEI N } \\ 13.146\end{array} \\ \mathbf{1 9 8 9} & \mathbf{1 9 9 9} & \mathbf{2 0 0 0} & \mathbf{2 0 0 4} & \mathbf{2 0 0 8} & \mathbf{2 0 1 5}\end{array}$

Fonte: Elaboração dos autores

\section{O aparato técnico}

As diretrizes construtivas podem ser apresentadas de duas formas (LEITE, 2016 e CALDEIRA, 2009). Primeiramente, em redações focadas no desempenho, quando é estabelecido o objetivo a ser alcançado, sem a definição de medidas, algo recorrente nas leis e decretos federais, ou seja, nos textos aprovados pela Câmara de Deputados Federais e o Senado e ratificados pela Presidência da República, como pode ser observando no exemplo descrito no Quadro 1, item I.

Quadro 1 - Exemplos para a diferença entre redações de desempenho e as descritivas

\begin{tabular}{|c|c|}
\hline \multicolumn{2}{|c|}{ Quadro 1 - Exemplos para a diferença entre redações de desempenho e as descritivas } \\
\hline $\begin{array}{c}\text { (I) Redação de } \\
\text { Desempenho }\end{array}$ & $\begin{array}{r}\text { Decreto 5.296/2004, Art. 12: Em qualquer intervenção nas vias e logradouros públicos, [...] } \\
\text { garantirão o livre trânsito e a circulação de forma segura das pessoas em geral, especialmente } \\
\text { das pessoas portadoras de deficiência ou com mobilidade reduzida [...]. }\end{array}$ \\
\hline $\begin{array}{c}\text { (II) Redação } \\
\text { Prescritiva }\end{array}$ & $\begin{array}{r}\text { ABNT NBR 9050:2015, item 6.12.3. Tópico c) faixa livre ou passeio: destina-se exclusivamente à } \\
\text { circulação de pedestres, deve ser livre de qualquer obstáculo, ter inclinação transversal até 3 \%, } \\
\text { ser contínua entre lotes e ter no mínimo 1,20 m de largura e 2,10 m de altura livre; }\end{array}$ \\
\hline
\end{tabular}

Fonte: Elaboração dos autores, baseado em ABNT (2015) e Brasil (2004).

Quando são necessários maiores detalhamentos teórico-científicos, recorre-se à segunda tipologia de redação, com caráter prescritivo, que prioriza as metragens exatas ou o intervalo dimensional admissível. Geralmente as normas técnicas possuem essa postura, sendo desenvolvidas por um órgão técnico, com o auxílio de especialistas no assunto e ratificadas pelas partes interessadas (Quadro 1, Item II).

Ambas as redações possuem pontos positivos e negativos no contexto da Acessibilidade e do Desenho Universal, devendo assim serem observadas como elementos complementares. Esse fato é reconhecido desde a Lei 7.853 de 1989 que sugere o atendimento às normas técnicas pertinentes ao assunto.

Os textos voltados ao desempenho são mais abrangentes e permitem uma maior flexibilidade no atendimento de suas disposições, entretanto, requerem um intérprete com maior conhecimento prévio. Voltando ao exemplo do Quadro 1, é necessário ter em mente as características que devem ser observadas em uma calçada para pedestres com ou sem deficiência e na sequência elaborar uma resposta projetual. $\mathrm{O}$ oposto ocorre com os textos prescritivos, que limitam, mas explicitam a 


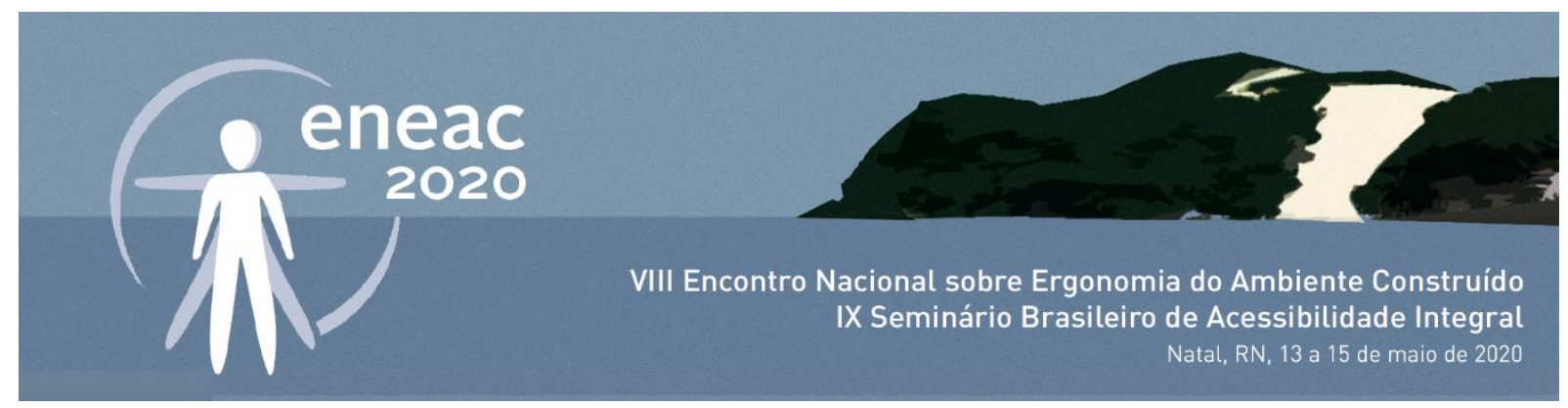

resposta, a calçada deve ter largura mínima de 1,20m. Uma mensagem clara, para os casos de baixo entendimento do assunto.

Embora Acessibilidade e o Desenho Universal estejam presentes no contexto legal brasileiro, desde a Constituição Federal até o mais simples decreto municipal, as normas técnicas desenvolvidas pela ABNT - Associação Brasileira de Normas Técnicas conformaram-se como os textos mais conhecidos para o assunto, tanto por técnicos como por leigos, justamente por sua abordagem predominantemente prescritiva.

\title{
3 AS QUATRO VERSÕES DA ABNT NBR 9050
}

$O$ atendimento às normas de Acessibilidade da ABNT tornou-se obrigatório a partir de 2004 com o Decreto no 5.296/2004, contudo a presença dessa instituição nos textos legais de outra natureza não é novidade, tendo sido iniciado em 1962 com a Lei ${ }^{\circ}$ 4.150:

\begin{abstract}
Art. 1 을 Nos serviços públicos concedidos pelo Govêrno Federal, assim como nos de natureza estadual e municipal por êle subvencionados ou executados em regime de convênio, nas obras e serviços executados, dirigidos ou fiscalizados por quaisquer repartições federais ou órgãos paraestatais, em tôdas as compras de materiais por êles feitas, bem como nos respectivos editais de concorrência, contratos, ajustes e pedidos de preços será obrigatória a exigência e aplicação dos requisitos mínimos de qualidade, utilidade, resistência e segurança usualmente chamados "normas técnicas" e elaboradas pela Associação Brasileira de Normas Técnicas, nesta lei mencionada pela sua sigla "ABNT" (BRASIL, 1962).
\end{abstract}

A ABNT é uma associação brasileira civil, sem fins lucrativos, com o objetivo de normatizar e certificar produtos e sistemas. Criada em 1940, inicialmente para atender a padronização requerida pela construção civil, passou com o tempo a normatizar outras temáticas, dentre elas a acessibilidade.

A participação dos usuários na elaboração das normas é um dos requisitos para a publicação da ABNT, como pode ser observado na Figura 2: o trâmite é iniciado com a apresentação de uma Demanda (1), tanto de pessoa física como jurídica, envolvida no assunto a ser normatizado. A proposta é previamente analisada pela ABNT (2), que ao constatar a viabilidade a encaminha para um Comitê Técnico. Atualmente existem 243 Comitês, dos mais diferentes assuntos, dentre eles o Comitê Brasileiro de Acessibilidade (ABNT/CB-040).

Figura 2 - Etapas para a publicação de Normas ABNT

\begin{tabular}{|l|l|l|l|l|l|l}
\hline 1. DEMANDA & $\begin{array}{l}\text { 2. ANÁLISE } \\
\text { PRÉVIA ABNT }\end{array}$ & $\begin{array}{l}\text { 3. ATUAÇÃO } \\
\text { COMITEE }\end{array}$ & $\begin{array}{l}\text { 4. CONSULTA } \\
\text { TÉCNICO }\end{array}$ & $\begin{array}{l}\text { 5. ANÁLISE DA } \\
\text { CONSULTA }\end{array}$ & $\begin{array}{l}\text { 6. PUBLICAÇÃO } \\
\text { DA NORMA }\end{array}$ \\
\hline
\end{tabular}

Fonte: Elaboração dos autores, baseado em ABNT (2019).

No Comitê, as discussões com as partes interessadas para a normatização (3) ocorrem no âmbito de uma Comissão de Estudo específica, que gera um Projeto de Norma, submetido à Consulta Pública (4). Os comentários e sugestões recepcionados são analisados pela Comissão (5) e, após o consenso de todos os envolvidos no processo, o texto é homologado e publicado (6) pela ABNT. 


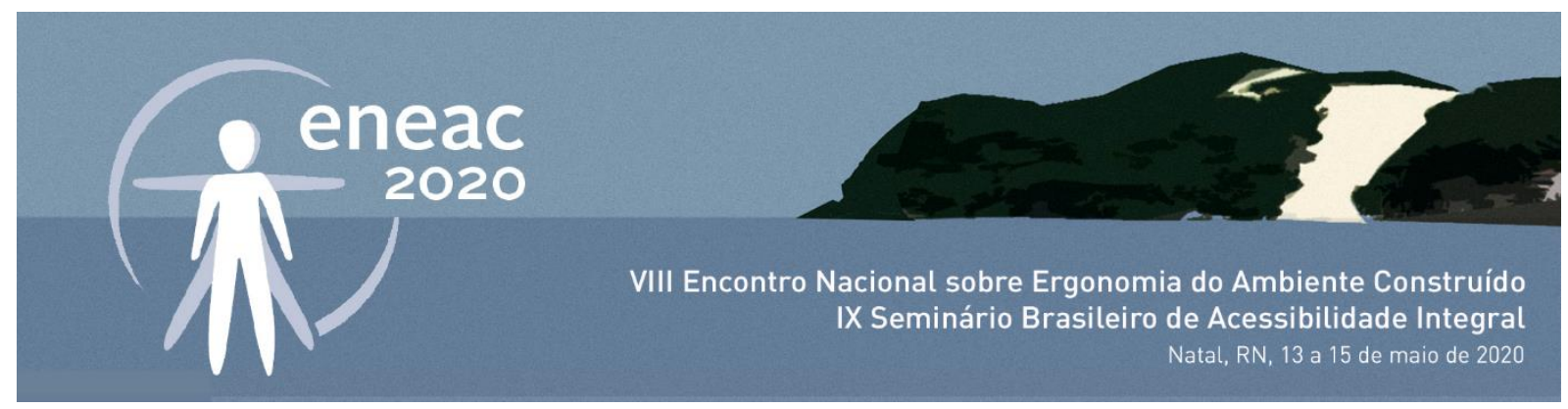

A ABNT NBR 9050 foi a primeira norma técnica com amplitude nacional voltada às necessidades das pessoas com deficiência. Por centralizar os principais assuntos relacionados à temática, tornou-se referência, sendo uma das redações mais conhecidas, tanto por técnicos como por leigos, para tratar a acessibilidade e o Desenho Universal. Atualmente está em sua quarta edição (Figura 3).

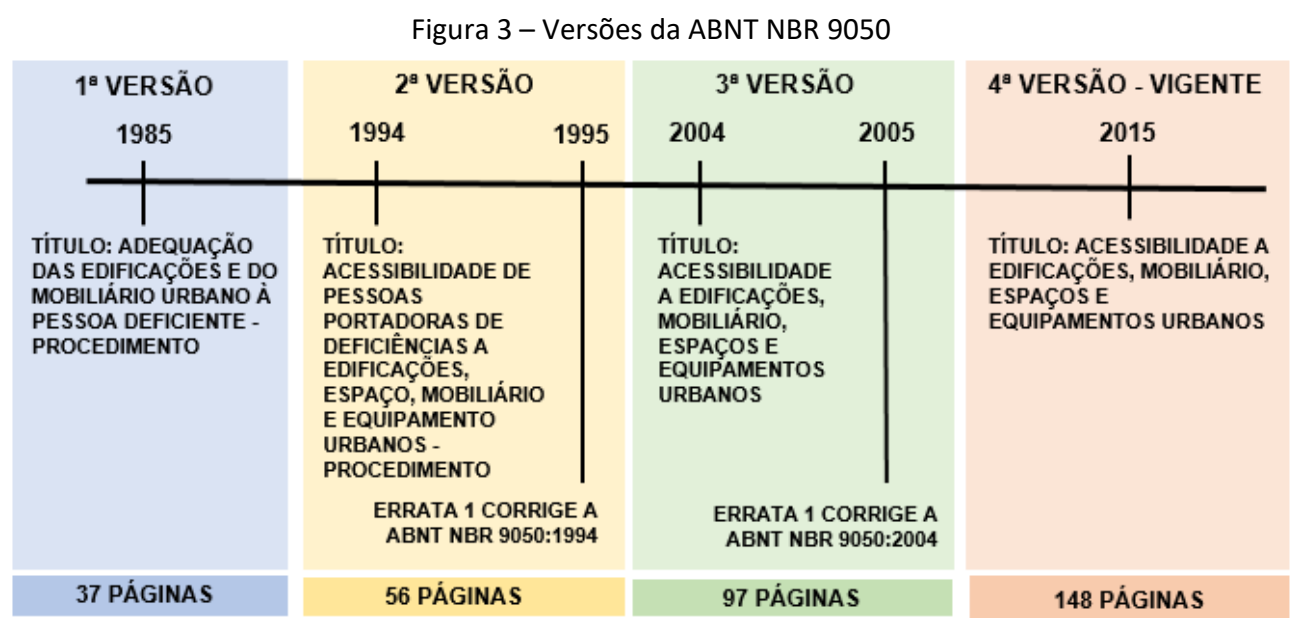

Fonte: Elaboração dos autores, baseado em ABNT (2019).

O primeiro texto da norma foi publicado em 1985, no mesmo período em que os Estados Unidos lançaram pela American National Standards Institute (ANSI) uma reedição da primeira norma de acessibilidade, de 1961, e quando os materiais da ONU para a Década da Pessoa com Deficiência eram disseminados no Brasil, motivando os movimentos em prol dos direitos das pessoas com deficiência, os quais resultaram nas ações em torno da Constituinte de 1988.

A ABNT NBR 9050:1985 possuía 37 páginas, elaboradas sob a responsabilidade do Comitê Brasileiro de Construção Civil, o CB-2, porque na época ainda não existia um órgão exclusivo para a acessibilidade. A origem do texto representou um avanço significativo, e não somente pelo conteúdo. Normas são elaboradas para questões reais, indo ao encontro das necessidades de pessoas percebidas pela sociedade, assim essa publicação representou a superação da invisibilidade presente no conceito de invalidez vigente na época.

Já no título, "Adequação das Edificações e do Mobiliário à Pessoa Deficiente", é demostrado o entendimento válido no período. No termo "adequação" nota-se a ideia de adaptação do edificado, e mesmo o acréscimo de solução acessível nas fases finais do projeto. Assim, distancia-se do conceito atual, em que o assunto é requisito desde os primeiros croquis.

De acordo com Leite (2016), em 1991 foi iniciada a primeira revisão da ABNT NBR 9050, concluída em 1994, sendo que em 1995 o texto ainda incorporou uma modificação, a Errata no 1. Com o título:

"Acessibilidade de pessoas portadoras de deficiência a edificações, espaços, mobiliário e equipamento", a norma foi ampliada para 56 páginas, sendo ainda direcionada para um grupo específico, entretanto, já incorporando o conceito de acessibilidade.

De acordo com Santos Filho (2010), a redação foi desenvolvida com a participação de funcionários do Metrô de São Paulo e de Secretarias do Estado de São Paulo, após o surgimento de ações judiciais em prol da acessibilidade em espaços públicos, com ganho de causa para pessoas com deficiência, 


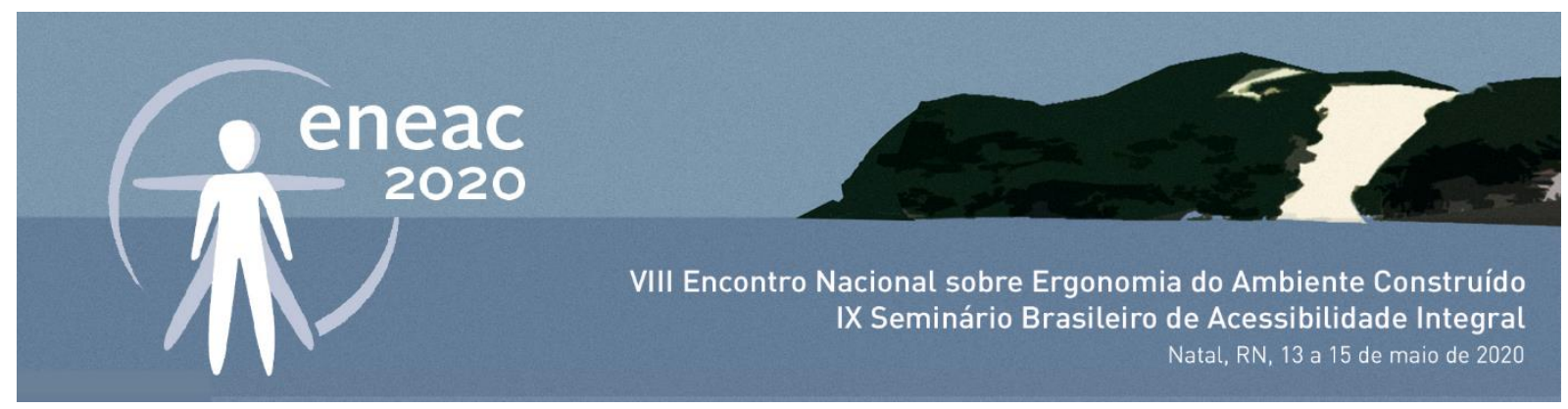

um resultado alcançado a partir das garantias legais estabelecidas no final da década de 1980. A mudança de "Pessoa Deficiente" para "Pessoa Portadora de Deficiência", retirando o foco da deficiência, também estava inserida nesse contexto e, segundo Moraes (2007) foi um avanço alcançado pelos movimentos sociais após a Constituinte de 1987/88.

Depois de dez anos da primeira revisão, ocorreu uma segunda, de acordo com Leite (2016), iniciada em 2000 e concluída em 2004, englobando a Errata no 1 em 2005. Pela primeira vez o trâmite deixou de ser conduzido pelo Comitê Brasileiro de Construção Civil, passando para o Comitê Brasileiro de Acessibilidade, o ABNT/CB-40, criado também em 2000.

O documento, ampliado para 97 páginas foi intitulado “Acessibilidade a edificação, mobiliário, espaço e equipamentos urbanos", abandonando o direcionamento para pessoas com deficiência. Esta foi uma transição alinhada ao conceito do Desenho Universal, em que as soluções devem atender a todos, independentemente da limitação.

Embora o atendimento às normas técnicas de acessibilidade, estivessem previstos no contexto legal desde a Lei no 7.853/1989, somente nessa terceira verão a ABNT NBR 9050 tornou-se gratuita. Em 2004, foi firmado um Termo de Ajuste de Conduta - TAC - com o Ministério Público no qual a ABNT e a Target Engenharia e Consultoria Ltda.

Segundo a ABNT (2015), a Comissão de Estudo de Acessibilidade em Edificações (CE-40:000.01) do Comitê Brasileiro de Acessibilidade elaborou, em 2012, um Projeto de Revisão da Norma ABNT NBR 9050, viabilizando sua publicação definitiva em 2015. O título da versão anterior foi mantido, diferentemente do número de páginas, que aumentou para 148.

Atualmente a norma está organizada em torno de seis temáticas: Informação e Sinalização; Acesso e Circulação; Sanitários, Banheiros e Vestiários; Mobiliário urbano; Mobiliário; e Equipamentos urbanos. O diferencial, em relação às disposições anteriores, são quatro anexos informativos ${ }^{\mathrm{iii}}-$ com $^{2}$ um exclusivo para tratar os conceitos do Desenho Universal - e direcionar as questões de sinalização tátil para um texto exclusivo, a ABNT NBR 16537:2016 - Acessibilidade: Sinalização tátil no piso, Diretrizes para a elaboração de projetos e instalações.

Se no trâmite para a construção de uma norma a presença dos seus usuários é um requisito, no processo de revisão não é diferente. Embora a versão de 2015 ainda esteja vigente, recentemente foi concluída a consulta pública para a realização de atualizações propostas pela Comissão de Estudo de Acessibilidade. Segundo o Catálogo da ABNT (2019), a Emenda 1 aguarda a conclusão de algumas análises para a publicação.

\section{AS ALTERAÇÕES DA ABNT NBR 9050 EM RESPOSTA ÀS NECESSIDADES DOS INTÉRPRETES}

Ao longo de três décadas, a ABNT NBR 9050 foi sendo ampliada, indo ao encontro das necessidades tanto dos usuários dos ambientes construídos, como dos leitores que traduziam seu conteúdo em soluções projetuais. Diante do desconhecimento do assunto, a redação foi adquirindo um viés pedagógico, percebido na escolha, quantidade e forma como os conceitos tidos como relevantes foram explorados ao longo das versões. 


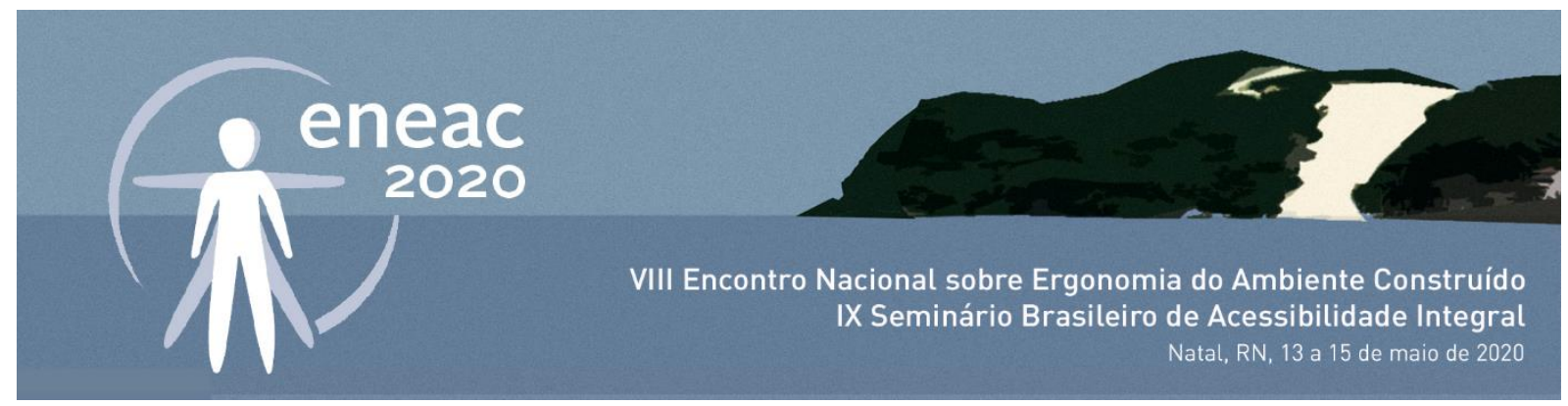

Antes de estabelecer medidas e requisitos mínimos, a redação de 1985 preparava o leitor, estabelecendo oito definições, sete para classificar a deficiênciaiv - incluindo a velhice - e uma para descrever a pessoa com deficiência de forma geral, como pode ser observado na Figura 4.

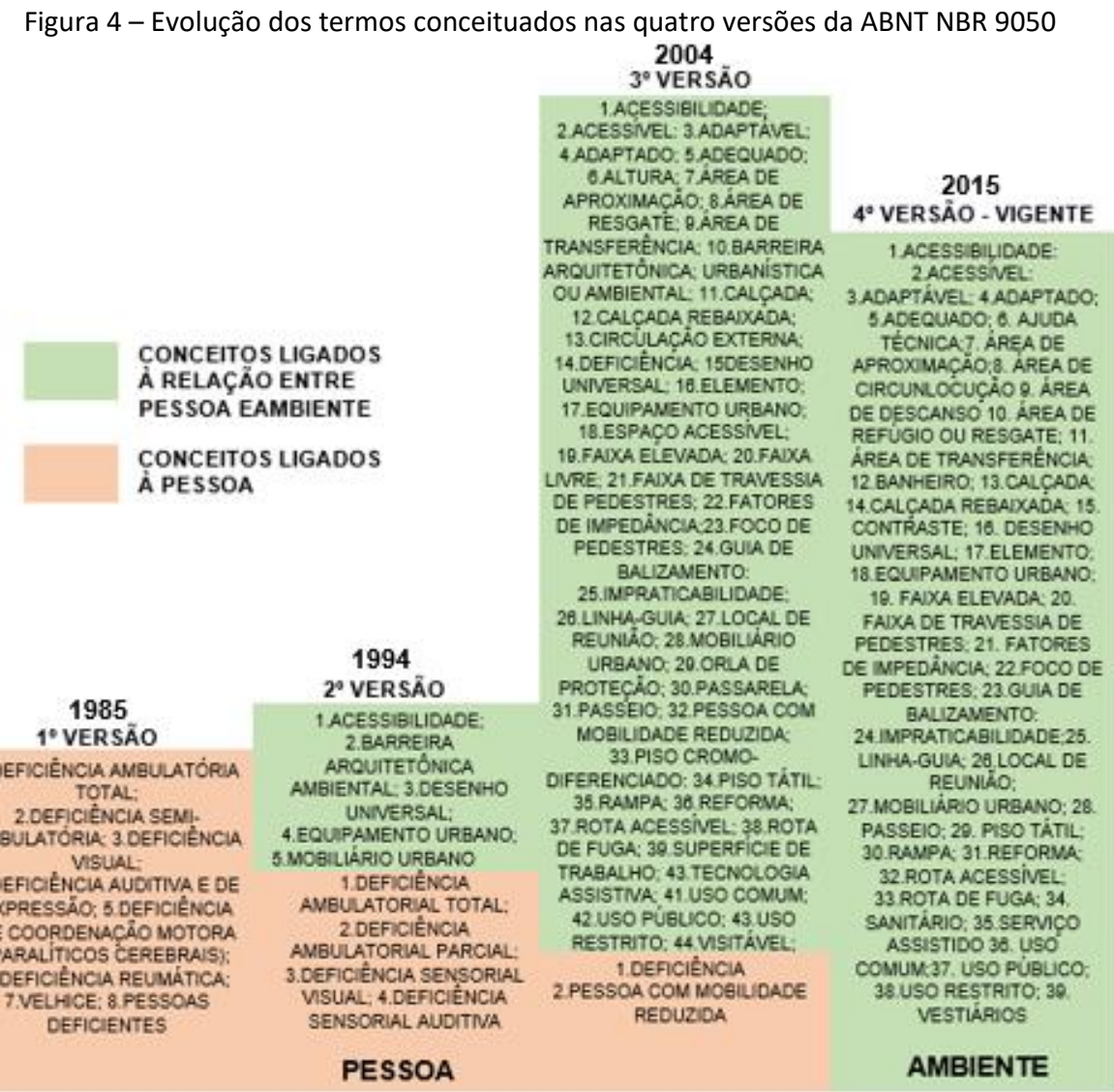

Fonte: Elaboração dos autores, baseado em ABNT (1985; 1994; 2004; 2015).

Em 1994, na segunda versão, foram conceituados nove termos, quatro relacionados às tipologias de deficiência das pessoas - deixando de considerar a velhice - e cinco para a relação entre indivíduo e ambiente. Após dez anos, verifica-se que ocorreu um salto do número de conceitos, sendo 2 para a pessoa e 44 para o meio. Em 2015, todas as 39 expressões são dedicadas ao ambiente.

Se, em 1985, não existiam termos para descrever a interação entre indivíduo e ambiente, denunciando uma segregação vigente na época, na última versão ocorreu justamente o contrário, a deficiência deixou de ser exclusivamente da pessoa, passando a ser da relação desta com o meio. Percebe-se aí um movimento de distanciamento do conceito médico de Acessibilidade e de aproximação da inclusão promovida pelo Desenho Universal.

Moraes (2007) compara as versões de 1985, 1994 e 2004, dividindo seus conteúdos em introdução, exposição de conceitos, apresentação de parâmetros antropométricos e determinação de critérios técnicos. Essa segmentação foi ampliada com a redação de 2015, conforme Figura 5. 

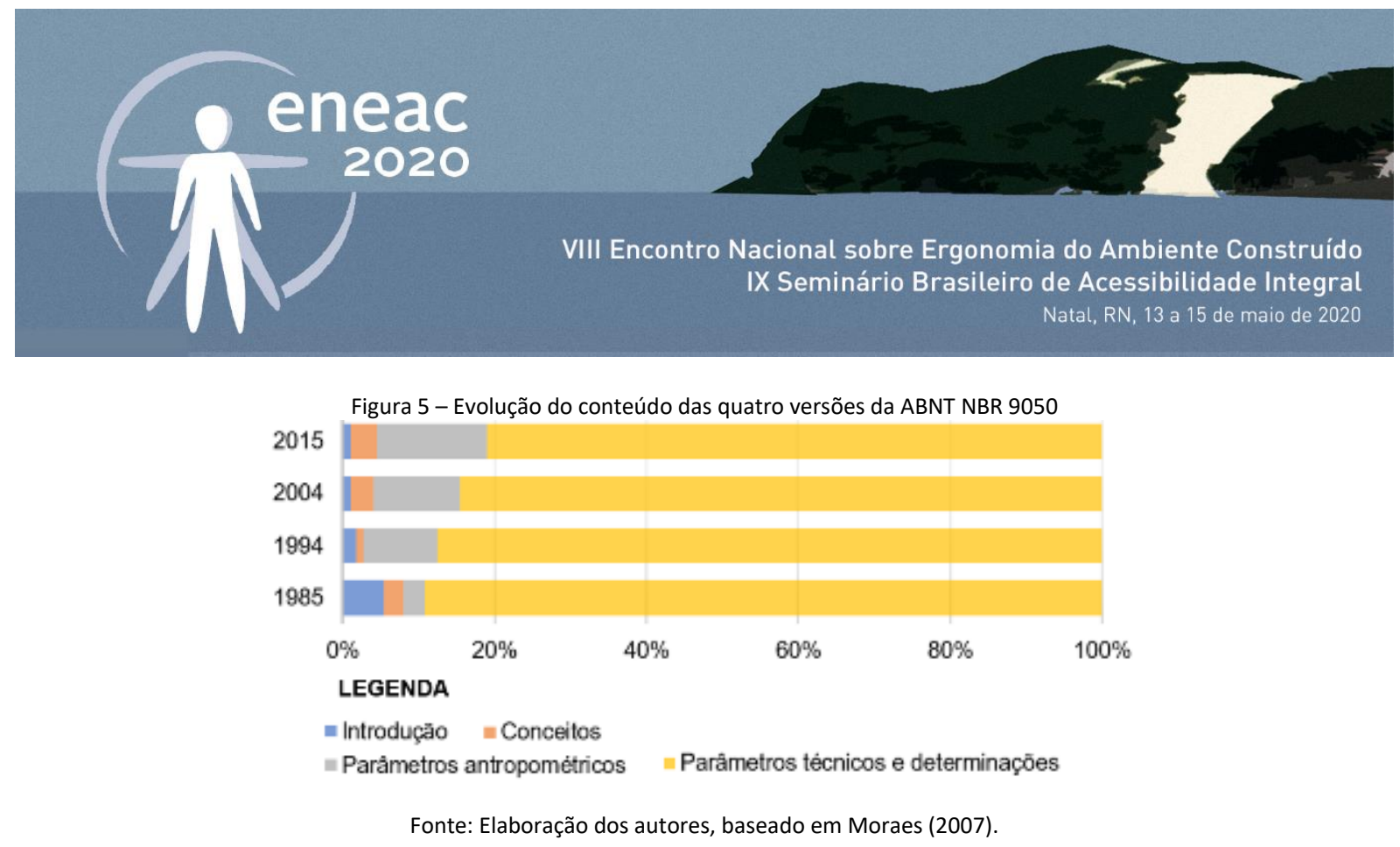

A vontade dos redatores da norma em trazer maiores explicações para o leitor antes das determinações, não ficou limitada aos conceitos e se repetiu nas proporções do conteúdo, com o crescimento da demonstração de conceitos e principalmente dos parâmetros antropométricos, ou seja, dos trechos que subsidiarão o entendimento das medidas e disposições mínimas e máximas dos trechos posteriores.

Se de um lado a falta de conhecimento contribuiu para a ampliação da norma, por outro, dificuldades em sua interpretação tornaram as definições mais precisas, principalmente as técnicas. Um exemplo ocorre com a sinalização em Braille no corrimão de escadas e rampas: em 2004, o item 5.12, B, descrevia a existência de "sinalização em Braille, informando sobre os pavimentos no início e no final das escadas fixas e rampas". Infelizmente o trecho era sensível a distorções. Executores, buscando economizar, realizaram a sinalização utilizando em todos os pavimentos as palavras em Braille "início" e "fim", sem distinguir o respectivo número do andar. Na versão de 2015, o texto foi explícito, determinando no item 5.4.3. que: "Os corrimãos de escadas fixas e rampas devem ter sinalização tátil (caracteres em relevo e em Braille), identificando o pavimento". E a frase vem acompanhada de ilustrações explicitando o fato.

Nesse processo de amadurecimento, com a ampliação e o aprofundamento de conceitos, o texto normativo superou divergências entre suas próprias designações, como as incompatibilidades entre a redação e as ilustrações, descritas por Moraes (2007). Entretanto, ainda existe espaço para melhorias, e o Conselho de Arquitetura e Urbanismo de São Paulo (CAU-SP) aponta dois deles no Boletim no 2 - GT Acessibilidade (CAU-SP, 2016).

O primeiro ponto é que o piso tátil de alerta nos patamares de rampas e escadas foi estabelecido no item 5.4.6.3, subitem E, da atual ABNT NBR 9050, entretanto não existem definições para a sua instalação; a própria ilustração 73 do item 6.6.4 - Patamares das rampas (Figura 6) - não contempla esse revestimento diferenciado. 


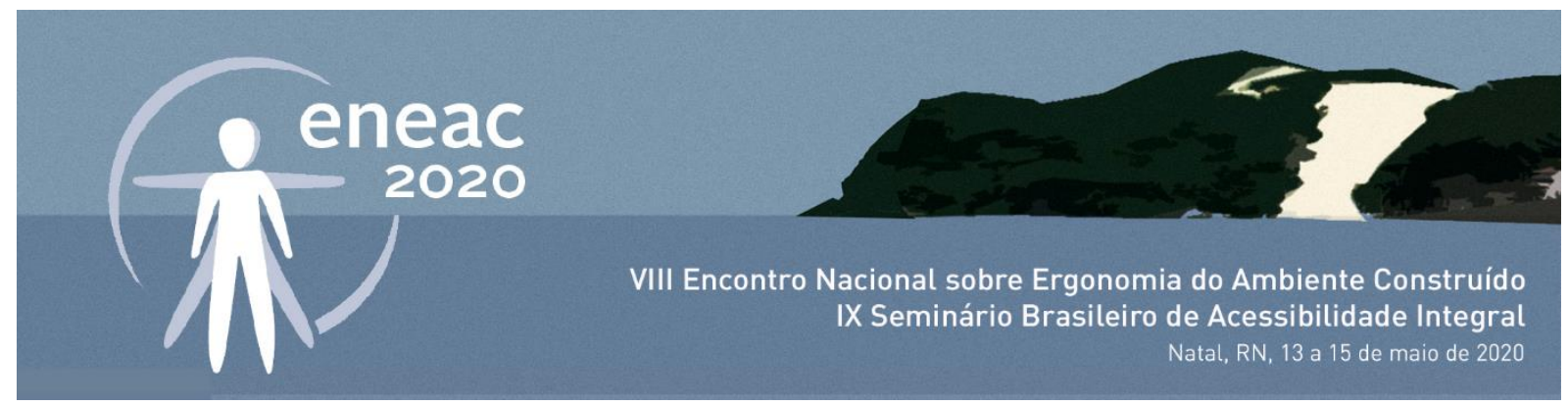

Figura 6 - Vista superior dos patamares das rampas

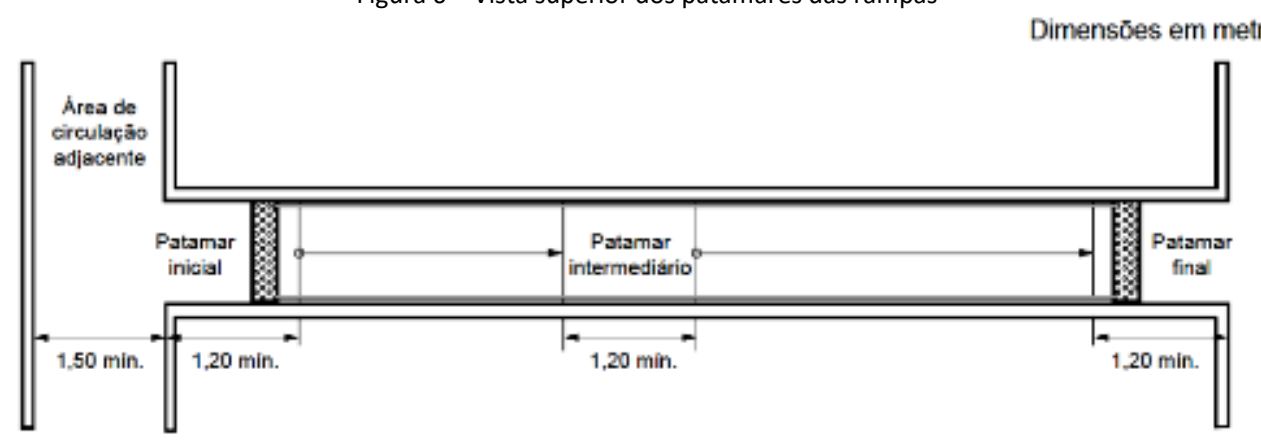

Fonte: ABNT (2015), originalmente a figura 73.

A questão foi corrigida, fora dessa norma, na ABNT NBR 16537:2016, exclusiva para a sinalização tátil no item 6.5.1:

Não pode haver sinalização tátil de alerta em patamares de escadas e rampas, em geral, cabendo aos corrimãos contínuos servir de linha-guia para orientar a circulação, conforme estabelece a ABNT NBR 9050 [...]. (ABNT, 2016, p. 14).

Um segundo ponto observado refere-se ao contraste visual entre matérias e superfícies, atendendo principalmente às necessidades das pessoas com baixa visão. No novo texto, essa característica é descrita em LRV (Light Reflectance Value, traduzido pela ABNT como Valor da Luz Refletida), uma métrica baseada na norma internacional ASTM C609-07 - Standard Test Method for Measurement of Light Reflectance Value and Small Color Differences Between Pieces of Ceramic Tile, na qual o branco equivale a 100 pontos e o preto, a 0 ponto. O CAU-SP reconhece a pertinência desse parâmetro, contudo observa com desconfiança a verificação do LRV por um equipamento específico definido pela norma.

\section{A INTERPRETAÇÃO DA ABNT NBR 9050}

Apesar de desempenhar um papel fundamental na difusão e padronização da Acessibilidade no contexto nacional, a ABNT NBR 9050 possui limitações decorrentes de tamanha complexidade e não pode ser a única fonte de consulta para atender às necessidades das pessoas com deficiência. Incompatibilidades estão presentes em seu interior e são até mesmo esperadas. Nenhum instrumento é perfeito, espelhando todas as facetas complexas, singulares e dinâmicas da realidade. Os tempos mudam, novas tecnologias surgem e o desconhecido torna-se conhecido, em uma velocidade desproporcional em relação ao trâmite necessário para o surgimento e validação dos textos normativos.

De acordo com Maximiliano (1984), o intérprete tem um papel fundamental, cabendo a ele reconhecer as limitações legais e perante o fato específico, aplicar as normas de acessibilidade ao meio físico, não como um fim, mas como um dos instrumentos para o desenvolvimento de projetos e obras que de fato atendam a todos.

Nessa perspectiva, a ausência de conhecimento ganha um movimento cíclico, contribuindo para a cristalização de uma realidade não vantajosa. Espaços acessíveis simplesmente para atender critérios 


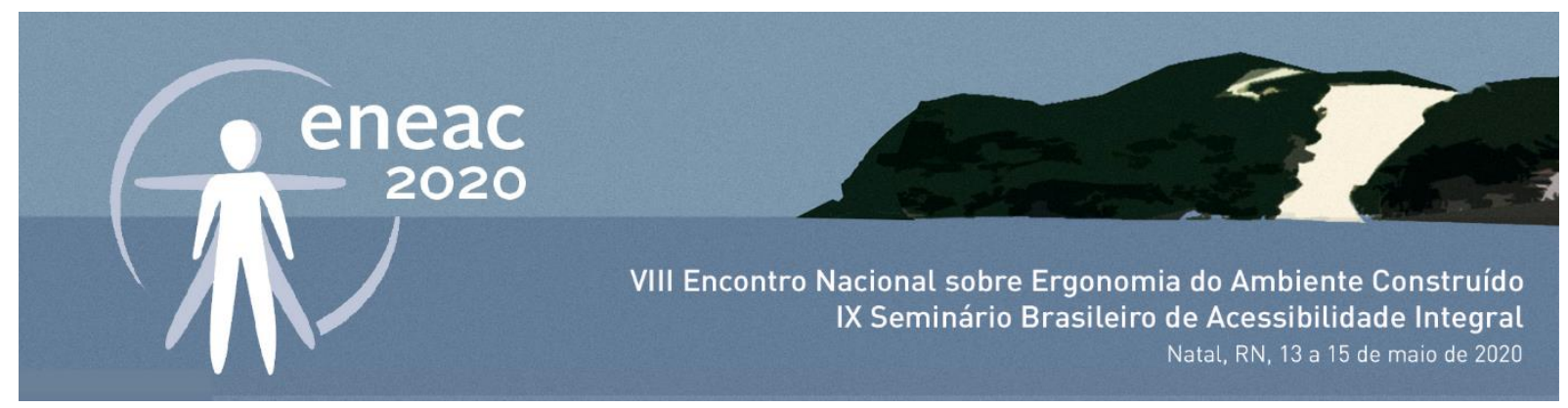

mínimos que não observam as necessidades das pessoas acabam favorecendo um entendimento equivocado do assunto também pelo público leigo, e esse, sem um outro referencial, dificilmente irá cobrar por avanços ou melhorias na área.

A questão pode ser exemplificada pela permanência da comercialização de vasos sanitários com um vão na porção frontal. Na versão da ABNT NBR 9050 de 2004, era apresentada a seguinte sequência de imagens (Figura 7), destituída de maiores explicações. Pelo seu título: "Exemplos de transferência para a bacia sanitária", o leitor deveria notar o movimento de um usuário de cadeira de rodas deslizando para o acento do vaso sanitário e deduzir que esse deslizamento seria possível pela continuidade de uma superfície.

Figura 7 - Exemplos de transferência para bacia sanitária

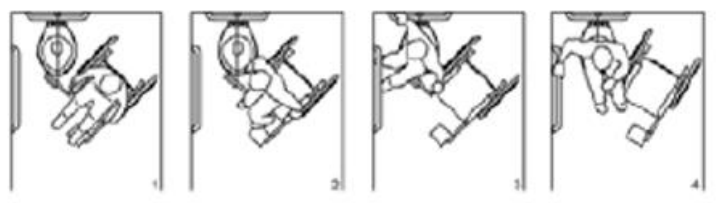

a) apoio à esquerda com cadeira de costas para parede de fundc

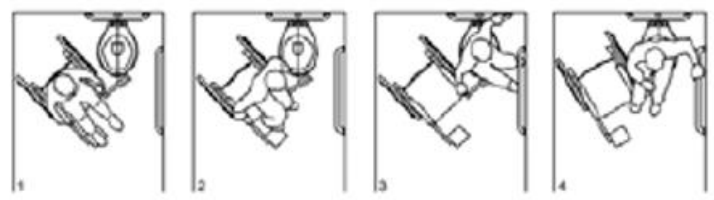

b) apoio a direita com cadeira de costas para parede ce fundo
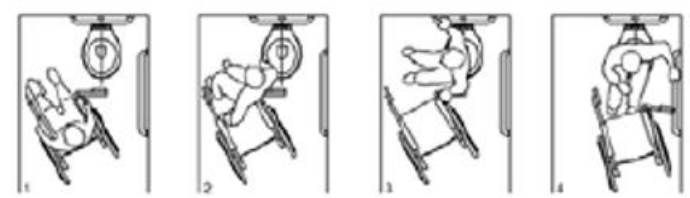

c) apoio à direita com cadeira de trente para parede de fundo
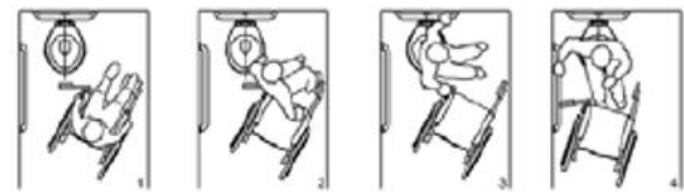

d) apoio à esquerda com cadeira de frente para parede de fundo

Fonte: ABNT NBR 9050 (2004), originalmente a Figura 115.

Após alguns acidentes, o texto de 2015 passou a ser enfático no item 7.7: "As bacias e assentos em sanitários acessíveis não podem ter abertura frontal" (ABNT NBR 9050, 2015). Mesmo diante dessa proibição, as bacias com abertura frontal continuam sendo comercializadas, residindo no entendimento popular como resposta à acessibilidade. Incrementar o conhecimento dos profissionais responsáveis pela produção do espaço é fundamental para o rompimento desse ciclo, melhorando o referencial do leigo, que retroalimenta o processo solicitando melhorias.

A Administração Pública tem buscado filtrar esse deficit nos processos seletivos para as admissões de seus quadros profissionais ${ }^{\vee}$. Em maio de 2016, o Conselho Nacional de Justiça, orientando a adequação do judiciário frente à Lei no 13.146, a LBI, estabeleceu, por meio da resolução CNJ 230/2016, que editais para concursos públicos na esfera judiciária deveriam prever a cobrança de conteúdos relacionados aos direitos das pessoas com deficiência:

Art. 19. Os editais de concursos públicos para ingresso nos quadros do Poder Judiciário e de seus serviços auxiliares deverão prever, nos objetos de avaliação, disciplina que abarque os direitos das pessoas com deficiência (CNJ, 2016).

Esse movimento se estendeu para processos seletivos de outras esferas. $O$ fato pode ser observado nos últimos três processos seletivos para o quadro de engenheiros civis e arquitetos e urbanistas da Caixa Econômica Federalvi. As provas são compostas por algumas questões de conhecimentos básicos, como português, ética, informática, matemática, direito, e administração pública, e por questões de conhecimento específico, abordando os assuntos técnicos pertinentes à engenharia e à arquitetura, dentre eles a acessibilidade e o Desenho Universal. 


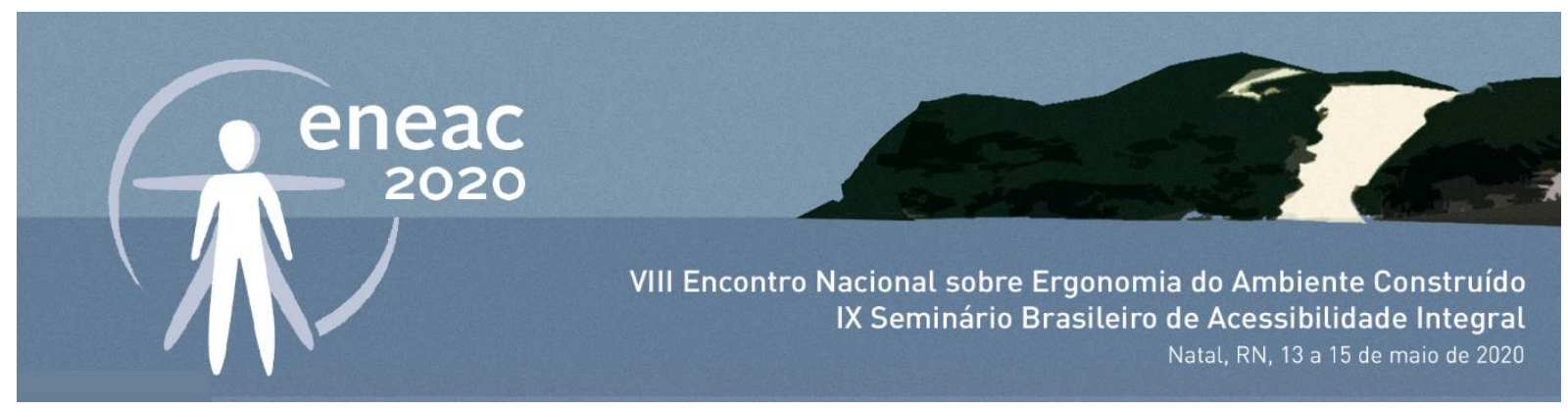

No Quadro 2 a seguir, é possível constatar que a presença da temática é constante, principalmente nas provas realizadas em 2010. Das 45 questões de conhecimento específico, oito para arquitetos e sete para engenheiros tratavam do assunto de forma praticamente indistinta entre os dois profissionais, repetindo as mesmas questões para ambos.

Quadro 2 - Número de questões de acessibilidade e Desenho Universal dos últimos três processos seletivos da Caixa Econômica Federal para arquitetos e engenheiros

\begin{tabular}{|c|c|c|c|c|c|c|}
\hline \multicolumn{2}{|c|}{ Data do Concurso } & \multicolumn{2}{|c|}{2010} & \multicolumn{2}{|c|}{2012} & \multirow{2}{*}{$\frac{2013}{\text { Eng. }}$} \\
\hline & Formação & Arq. & Eng. & Arq. & Eng. & \\
\hline \multirow{4}{*}{$\begin{array}{c}\text { Número } \\
\text { de } \\
\text { Questões }\end{array}$} & $\begin{array}{c}\text { Acessibilidade e } \\
\text { Desenho Universal }\end{array}$ & 8 & 7 & 4 & 2 & 1 \\
\hline & $\begin{array}{l}\text { Conhecimento } \\
\text { Específico }\end{array}$ & \multicolumn{4}{|c|}{45} & 40 \\
\hline & $\begin{array}{c}\text { Conhecimento } \\
\text { Básico }\end{array}$ & \multicolumn{4}{|c|}{15} & 20 \\
\hline & Total & \multicolumn{4}{|c|}{60} & 60 \\
\hline
\end{tabular}

Fonte: Elaboração dos autores, baseado em Caixa (2019).

Após 2010, os processos seletivos com questões de múltipla escolha passaram a contar também com questões discursivas. Assim, embora tenha sido reduzido o número de perguntas relacionadas à Acessibilidade e ao Desenho Universal em 2012 e 2013, o assunto passou a ser solicitado de forma mais profunda, requerendo redações com 20 a 30 linhas. Na prova para engenheiros em 2012, por exemplo, foi apresentada uma rampa em rota acessível, sendo solicitado que o candidato elaborasse um texto analisando a sua conformidade com as normas técnicas pertinentes.

Embora a cobrança desse conteúdo em processos seletivos represente um avanço significativo no alinhamento de esforços para o cumprimento dos marcos regulatórios, por se tratar de uma questão ampla, relacionada desde as redações dos normativos às dificuldades dos leitores em interpretá-los, a implementação da Acessibilidade e do Desenho Universal requerem maiores e contínuos investimentos.

\section{CONSIDERAÇÕES FINAIS}

Ao comparar a Norma ABNT NBR 9050 de 2004 com textos internacionais vii, Moraes (2007) concluiu que embora existam problemas, o texto brasileiro possui vantagens em relação aos demais, algo reconhecido inclusive pela comunidade internacional, que de acordo com a ABNT (2015), considerou esse material para a elaboração da primeira norma técnica de acessibilidade com âmbito mundial, a ISO 21542:2011 - Building Construction - Accessibility and Usability of the Built Environment ${ }^{\text {viii. A }}$ mesma situação se repete na versão vigente, cuja redação, mesmo sendo voltada para um leitor com conhecimento técnico, não deixa de detalhar conceitos básicos.

Entretanto o sucesso de leis e normas não está somente vinculado a quantidade de erros e acertos no interior das redações, sendo também dependente na forma como são conduzidos por seus intérpretes. Geralmente o aparato legal é respeitado por dois princípios, o jurídico e o moral. 0 primeiro ocorre devido às consequências que a desobediência causa ao indivíduo e requer um grande poder de coação. Enquanto no segundo, o indivíduo segue o aparato legal naturalmente, por estar alinhado aos seus valores. 


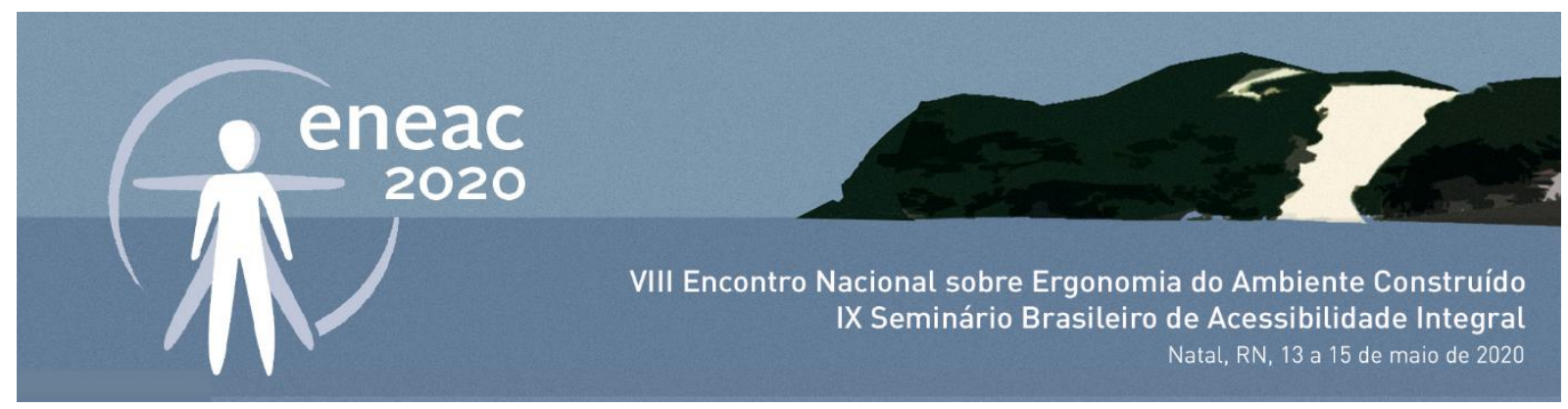

A questão da acessibilidade e do Desenho Universal se reveste de assunto exclusivamente técnicojurídico quando observada pelo intérprete da lei como algo desprovido de sentido. Os requisitos mínimos são atendidos apenas para cumprir o texto, sendo necessários, para isso, vários mecanismos burocráticos. No entanto, quando o indivíduo tem consciência dos objetivos legais e de suas razões, passa a encarar as necessidades das pessoas como um princípio moral, aumentando e potencializando a probabilidade do atendimento deste com eficiência. Nesse sentido, estratégias alinhadas a tal entendimento são relevantes, contribuindo para o surgimento de ambientes mais justos e naturalmente alinhados aos aparatos legais e técnicos.

\section{REFERÊNCIAS}

ABNT - Associação Brasileira de Normas Técnicas. ABNT NBR 9050/1985: Adequação das edificações e do mobiliário urbano à pessoa deficiente. Rio de Janeiro, 1985.

. ABNT NBR 9050/1995: Acessibilidade de pessoas portadoras de deficiência a edificações, espaço, mobiliário e equipamento urbanos. Rio de Janeiro, 1995. 2005.

ABNT NBR 9050/2005: Acessibilidade a edificações, mobiliário, espaços e equipamentos urbanos. Rio de Janeiro,

_._. ABNT NBR 9050/2015: Acessibilidade a edificações, mobiliário, espaços e equipamentos urbanos. Rio de Janeiro, 2015.

. ABNT NBR 16537/2016: Acessibilidade - Sinalização tátil no piso, diretrizes para a elaboração de projetos e instalações. Rio de Janeiro, 2016.

. Boletim ABNT. Acessibilidade, um direito de todos. Nov./dez. 2015, v. 12, no 148. Rio de Janeiro: ABNT, 2015.

Catálogo. Busca mediante o número da norma (9050). Adotando os status: "em vigor" e "cancelada". 2019.

Disponível em: <https://www.abntcatalogo.com.br/default.aspx>. Acesso em: 23/12/2019.

Catálogo - Projeto de revisão de emenda ABNT NBR 9050. 2019. Disponível em:

<https://www.abntcatalogo.com.br/projet.aspx?ID=8639>. Acesso em: 23/12/2019.

ARAUJO, Luiz Alberto David. A proteção constitucional das pessoas portadoras de deficiência. Brasília: Coordenadoria Nacional para Integração da Pessoa Portadora de Deficiência, 1997.

BRASIL. Constituição (1988). Constituição da República Federativa do Brasil. Promulgada em 5 de outubro de 1988. Disponível em: <http://www.planalto.gov.br/ccivil_03/Constituicao/Constituicao.htm>. Acesso em: 04/06/2019.

. Decreto no 3.298 de 20 de dezembro de 1999. Regulamenta a Lei no 7.853, de 24 de outubro de 1989, dispõe sobre a Política Nacional para a Integração da Pessoa Portadora de Deficiência, consolida as normas de proteção e dá outras providências. Disponível em: <http://www.planalto.gov.br/ccivil_03/decreto/d3298.htm>. Acesso em: 24/08/2018.

Decreto no 5.296 de 2 de dezembro de 2004. Regulamenta as Leis nos 10.048, de 8 de novembro de 2000, que dá prioridade de atendimento às pessoas que especifica, e 10.098, de 19 de dezembro de 2000, que estabelece normas gerais e critérios básicos para a promoção da acessibilidade das pessoas portadoras de deficiência ou com mobilidade reduzida, e dá outras providências. Disponível em: <http://www.planalto.gov.br/ccivil_03/_Ato20042006/2004/Decreto/D5296.htm>. Acesso em: 24/08/2018.

Decreto Legislativo no 186 de 10 de julho de 2008. Aprova o texto da Convenção sobre os Direitos das Pessoas com Deficiência e de seu Protocolo Facultativo, assinados em Nova lorque, em 30 de março de 2007. Disponível em: <https://www2.camara.leg.br/legin/fed/decleg/2008/decretolegislativo-186-9-julho-2008-577811-publicacaooriginal100742-pl.html>. Acesso em: 06/06/2019. 


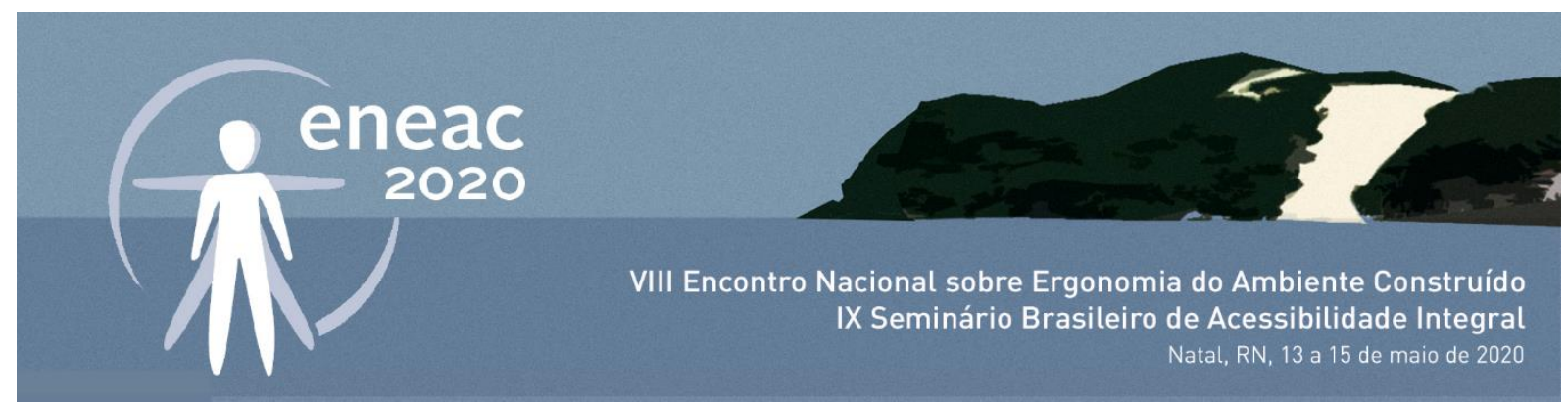

. Emenda Constitucional $n^{\circ} 12$ de 17 de outubro de 1978. Assegura aos deficientes a melhoria de sua condição social e econômica. Disponível em: <http://www.planalto.gov.br/ccivil_03/constituicao/Emendas/Emc_anterior1988/emc1278.htm>. Acesso em: 06/06/2019.

. Lei $n^{\circ} 4.150$ de 21 de novembro de 1962. Institui o regime obrigatório de preparo e observância das normas técnicas nos contratos de obras e compras do serviço público de execução direta, concedida, autárquica ou de economia mista, através da Associação Brasileira de Normas Técnicas, e dá outras providências. Disponível em: <http://www.planalto.gov.br/ccivil_03/leis/1950-1969/L4150.htm>. Acesso em: 04/06/2018.

. Lei no 7.853 em 24 de outubro de 1989. Dispõe sobre o apoio às pessoas portadoras de deficiência, sua integração social, sobre a Coordenadoria Nacional para Integração da Pessoa Portadora de Deficiência - Corde, institui a tutela jurisdicional de interesses coletivos ou difusos dessas pessoas, disciplina a atuação do Ministério Público, define crimes, e dá outras providências. Disponível em: <http://www.planalto.gov.br/ccivil_03/leis/L7853.htm>. Acesso em: 04/06/2018.

. Lei no 8.429 de 2 de junho de 1992. Dispõe sobre as sanções aplicáveis aos agentes públicos nos casos de enriquecimento ilícito no exercício de mandato, cargo, emprego ou função na administração pública direta, indireta ou fundacional e dá outras providências. Disponível em: <https://www2.camara.leg.br/legin/fed/lei/1992/lei-8429-2-junho1992-357452-normaatualizada-pl.html>. Acesso em: 22/12/2019.

. Lei no 10.098 de 19 de dezembro de 2000b. Estabelece normas gerais e critérios básicos para a promoção da acessibilidade das pessoas portadoras de deficiência ou com mobilidade reduzida, e dá outras providências. 2000b. Disponível em: <http://www.planalto.gov.br/ccivil_03/LEIS/L10098.htm>. Acesso em: 04/06/2018.

. Lei $n^{\circ} 10.257$ de 10 de julho de 2001. Regulamenta os arts. 182 e 183 da Constituição Federal, estabelece diretrizes gerais da política urbana e dá outras providências. (Estatuto das Cidades). Disponível em: <http://www.planalto.gov.br/ccivil_03/LEIS/LEIS_2001/L10257.htm>. Acesso em: 22/12/2019.

. Lei no 13.146 de 6 de julho de 2015. Institui a Lei Brasileira de Inclusão da Pessoa com Deficiência (Estatuto da Pessoa com Deficiência ou Lei Brasileira de Inclusão). Disponível em: <http://www.planalto.gov.br/ccivil_03/_ato20152018/2015/lei/l13146.htm>. Acesso em: 04/06/2018.

CAIXA ECONÔMICA FEDERAL. Concurso Público - Provas de concurso 2019. Editais, provas e gabaritos de processos seletivos. 2019. Disponível em: <http://www.caixa.gov.br/site/paginas/downloads.aspx>. Acesso em: 24/12/2019.

CALDEIRA, Isabel Maria Fernandes Pereira. Espaço público para todos: aplicação dos princípios da acessibilidade plena em áreas históricas e em áreas consolidadas. Dissertação (Mestrado em Engenharia Civil) - Universidade do Porto, 2009.

CAU/SP - Conselho de Arquitetura e Urbanismo de São Paulo. Boletim no 2 - GT Acessibilidade. 2016. Disponível em: $<$ https://www.causp.gov.br/boletins-gt/boletins-gt-acessibilidade/>. Acesso em: 23/12/2019.

CNJ - Conselho Nacional de Justiça. CNJ 230/2016 de 22 de junho de 2016. Orienta a adequação das atividades dos órgãos do Poder Judiciário e de seus serviços auxiliares às determinações exaradas pela Convenção Internacional sobre os Direitos das Pessoas com Deficiência e seu Protocolo Facultativo e pela Lei Brasileira de Inclusão da Pessoa com Deficiência por meio - entre outras medidas - da convolação em resolução à Recomendação CNJ 27, de 16/12/2009, bem como da instituição de Comissões Permanentes de Acessibilidade e Inclusão. Disponível em: <https://atos.cnj.jus.br/atos/detalhar/atosnormativos?documento=2301>. Acesso em: 22/12/2019.

CRESPO, Ana Maria Morales. Da invisibilidade à construção da própria cidadania. Tese (Doutorado em História Social) Faculdade de Filosofia, Letras e Ciências Humanas da Universidade de São Paulo. São Paulo, 2009.

DORNELES, Vanessa Goulart. Estratégias de ensino de Desenho Universal para cursos de graduação em Arquitetura e Urbanismo. Tese (Doutorado em Arquitetura e Urbanismo) - Programa de Pós-Graduação em Arquitetura e Urbanismo Pós ARQ, Universidade Federal de Santa Catarina. Florianópolis, 2014.

ISO, 2019. Developing Standards. Disponível em: <https://www.iso.org/developing-standards.html>. Acesso em: 22/12/2019. 


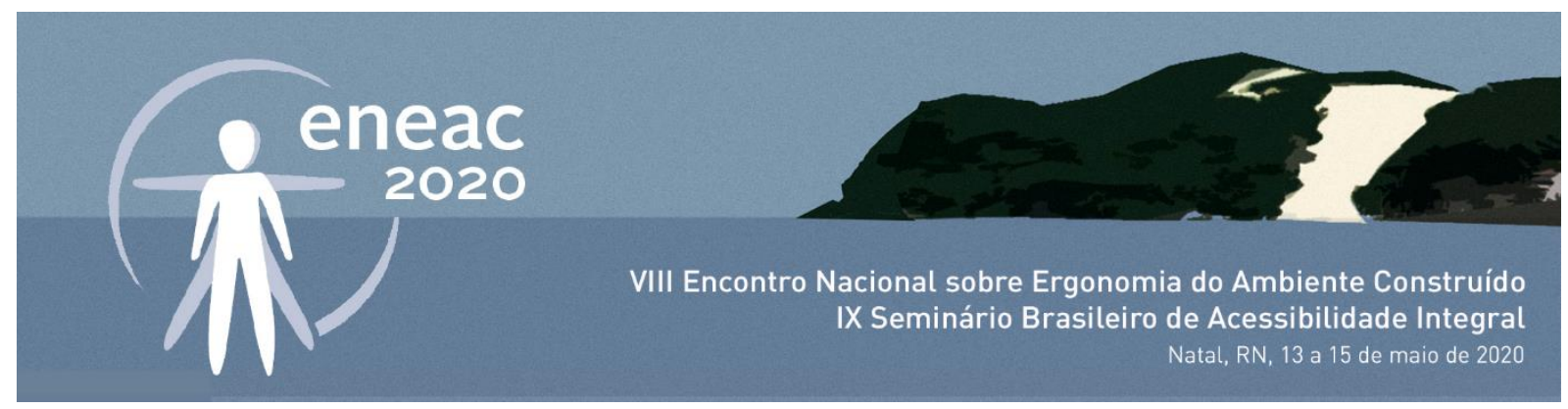

LEITE, Mariana Azevedo de Lima. A NBR 9050 e o Design Universal: um estudo sobre o banheiro. Dissertação (Mestrado em Arquitetura e Urbanismo) - Universidade Federal do Rio Grande do Norte. Natal, 2016.

MACE, Roland; HARDIE, Graeme J.; PLACE, Jaime P. Accessible Environments: Toward the Universal Design. New York, USA: North Carolina State University, 1991.

MAXIMILIANO, Carlos. Hermenêutica e aplicação do direito. 9a ed. Rio de Janeiro: Forense, 1984.

Ministério da Educação. Resolução no 2/2010. Institui as Diretrizes Curriculares Nacionais do curso de graduação em Arquitetura e Urbanismo, alterando dispositivos da Resolução CNE/CES no 6/2006. 2010. Disponível em: $<$ http://portal.mec.gov.br/index.php?option=com_docman\&view=download\&alias=5651-rces002-10\&ltemid=30192>. Acesso em: 22/12/2019.

Relatório. Alteração da Resolução CNE/CES no 2, de 17 de junho de 2010, que institui as Diretrizes Curriculares Nacionais do Curso de Graduação em Arquitetura e Urbanismo, bacharelado, e alteração da Resolução CNE/CES no 2, de 24 de abril de 2019, que institui as Diretrizes Curriculares Nacionais do Curso de Graduação em Engenharia, em virtude de decisão judicial transitada em julgado. 2019. Disponível em:

<http://portal.mec.gov.br/index.php?option=com_docman\&view=download\&alias=128041-pces94819\&category_slug=outubro-2019\&Itemid=30192>. Acesso em 04/03/2020.

MORAES, Miguel Correia de. Acessibilidade no Brasil: análise da NBR 9050. Dissertação (Mestrado em Arquitetura e Urbanismo) - Programa de Pós-Graduação em Arquitetura e Urbanismo PósARQ, Universidade Federal de Santa Catarina. Florianópolis, 2007.

PADOAM, Flávia. Do estudante ao profissional consciente: a inserção da acessibilidade e do Desenho Universal no curso de Engenharia Civil. Monografia (Trabalho Final de Curso) - Faculdade de Engenharia Civil, Arquitetura e Urbanismo. Universidade Estadual de Campinas. Campinas, 2018.

SANTOS FILHO, Gildo Magalhaes dos. Construindo um Itinerário Histórico do Desenho Universal: A Normatização Nacional e Internacional da Acessibilidade. In: Ornstein, Sheila Walbe; ALMEIDA PRADO, Adriana Romeiro; LOPES, Maria Elisabete. Desenho Universal: Caminhados da Acessibilidade no Brasil. São Paulo: Annablume, 2010, p. 35-55.

SILVA, Otto Marques da. A epopeia ignorada: a pessoa deficiente na história do mundo de ontem e de hoje. São Paulo: Cedas, 1987.

\footnotetext{
' Na literatura existem várias denominações para o conceito: Desenho Universal, universal design e design universal. Independentemente das nuances estabelecidas, todas as terminologias residem na mesma premissa: atender o maior número de pessoas, respeitando as singularidades. Em razão de a temática do presente trabalho estar relacionada ao atendimento dos marcos nacionais, a expressão adotada na redação será Desenho Universal, devido à sua predominância na legislação vigente.

ii Em 9 de outubro de 2019 o Conselho Nacional de Educação do Ministério da Educação publicou a aprovação de um Relatório que atualmente aguarda homologação e sugere mudanças nas diretrizes nacionais curriculares das graduações de Engenharia e Arquitetura e Urbanismo (Ministério da Educação, 2019). Segundo o texto a partir do ano letivo de 2020 deve ser implantada a disciplina de Desenho Universal nos respectivos cursos. O assunto vinha sendo discutido na Câmara da Educação de Ensino Superior desde 2013, contudo, recebeu um impulso maior com uma recente ação civil pública pleiteada pelo Ministério Público Federal.

iii O primeiro anexo apresenta os sete conceitos do Desenho Universal e o segundo contempla fatores relevantes para o projeto, como o LRV (Light Reflectance Value), uma métrica que favorece a padronização do contraste visual em superfícies. Requisitos para a fabricação de barras de apoio são contemplados no terceiro anexo, sendo que o quarto e último estabelece brevemente critérios para os sanitários utilizados por pessoas ostomizadas.

iv Na versão de 1985, a ABNT NBR 9050 classificava a deficiência em: 1. Física (deficiência ambulatória total); 2 . Física (deficiência semiambulatória); 3. Visual; 4. Auditiva e de Expressão; 5. De Coordenação Motora (paralíticos cerebrais); 6. Reumática; e 7. Velhice. ${ }^{v}$ Atendendo a Constituição Federal, artigo 37, inciso II, a atuação junto à Administração Pública deve ocorrer mediante um processo seletivo, composto por provas ou provas de títulos. Os requisitos para os interessados participarem desse processo, bem como a descrição dos conteúdos das provas são estabelecidos por um edital direcionado especificamente para um determinado concurso.

vi Editais no 1/2010/NS de março de 2010, n 1/2012/NS de fevereiro de 2012 para engenheiros e arquitetos, e o Edital no 1/2013/NS, exclusivo para engenheiros.

vii Moraes, 2007, Compara a Brasileira ABNT NBR 9050 de 2004 com as norte americanas, ADA - American with Disabilities Act juntamente com a ABA - The Architectural Barriers Act revisadas em 2004, a norma GDN de Luxemburgo, recomendada pela ECA - European Concept for Accessibility de 1997 e o Manual de Acessibilidade Integral das comunidades espanholas Castilla e La Mancha de 2003.

viii A presente norma foi desenvolvida pela International Organization for Standardization (ISO), uma organização aliada à Unesco e destinada à padronização de atividades que facilitem o intercâmbio internacional. De acordo com a própria ISO (2019), seus textos são elaborados com o auxílio de delegações nacionais e a contribuição de vários órgãos técnicos, dentre eles a brasileira ABNT.
} 